\title{
ФОЛЬКЛОР
}

\author{
О.В. Флеров
}

\section{ЭСКИМОССКИЕ ЯЗЫКИ В КОНТЕКСТЕ СОЦИАЛЬНО-ЭКОНОМИЧЕСКОЙ И ГЕОПОЛИТИЧЕСКОЙ ПРОБЛЕМАТИКИ}

\begin{abstract}
Аннотация. Объектом исследования в статье являются языки эскимосской группы. Предметом исследования выступают их место, статус и перспективы в контексте программ освоения арктических акваторий и прибрежных зон нашей страны. Автором выделяются особенности эскимосских языков как с чисто лингвистической, так и с сочиолингвистической точки зрения. Особое внимание уделяется статусу и перспективам эскимосских языков в контексте проблем поиска компромисса между освоением Российской Арктики и сохранением культуры коренных народов Севера.

Методом исследования в статье является лингвистический, социально-экономический и геополитический анализ настоящего положения и перспектив эскимосских языков как языков малых народов.

Основные выводы автора сводятся к тому, что сохранение культуры малых народов в эпоху технического прогресса, инноваций и модернизации невозможно без поддержания и повышения статуса их языков. В России эскимосские языки находятся в гораздо большей опасности, нежели в Северной Америке или Гренландии. Одним из путей поддержки эскимосских языков как элемента самобытной культуры может быть повышение интереса к их изучению в качестве иностранных, тем более что экзотические в целом языки пользуются определенным спросом в срере образования. Новизна статьи заключается в том, что эскимосские языки рассмотрены в ней не только с чисто языковой и культурологической, но и с социально-экономической, $а$ также с геополитической точки зрения.
\end{abstract}

Ключевые слова: язык, эскимосы, культура, Арктика, общество, политика, экономика, сохранение, Крайний Север, малые народы.

Review: The object of research in this article is Eskimo languages. The subject of research is their place, status and prospects in the context of Russian Arctic coasts exploration. The author distinguishes linguistic and socio-linguistic peculiarities of Eskimo languages. Particular attention is paid to the status and prospects of Eskimo languages in the context of looking for a compromise between Russian Arctic exploration and preserving culture of native North peoples. The method of research in this article is linguistic, social, economical and geopolitical analysis of the present state and prospects of Eskimo languages as minor peoples' dialects. The main author's conclusions come down to the following. Preservation of minor cultures in the epoch of technical progress, innovations and modernization is impossible without sustaining and raising their language status. In Russia Eskimo languages are on the verge of extinction unlike in North America and Greenland. One of the ways of supporting Eskimo languages may be raising interest for their learning as foreign languages, especially taking into account the fact that exotic languages are on certain demand today. The novelty of the article is caused by the fact that the author views Eskimo languages not only in terms of linguistics and culture but also in terms of social, economic and geopolitical studies.

Keywords: preservation, economy, politics, society, the Arctic Region, culture, the Eskimos, language, Polar North, minor peoples.

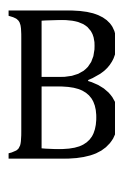

последнее время очень много говорится о проблемах освоения Арктики в контексте использования потенциала морских акваторий и прибрежных зон нашей страны.
Являясь самым большим государством по площади в мире, Россия обладает огромным экономическим потенциалом, открытие и использование которого является одной из приоритетных задач в 
условиях поиска новых путей экономического развития в эпоху нестабильности.

Технический и экономический прогресс регионов Крайнего Севера поспособствовал бы не только использованию ресурсного потенциала данной местности, но и созданию благоприятных социально-экономических условий для жизни и работы в них, что позволило бы местному обществу и населению выйти на новый уровень развития $[1 ; 2 ; 3 ; 4]$.

Между тем техническое развитие, инновационность и модернизация зачастую являются губительными факторами для самобытной и малоизвестной (за исключением стереотипных представлений и образов) культуры малых народов. Эти народы, которых в России насчитывается несколько десятков, с древнейших времён населяют неосвоенные технологически территории. Между тем для них эти местности являются освоенными в культурно-историческом плане, поскольку территории, на которых развивался социум, являются важной составляющей его национально-культурной идентичности, которая не может подвергаться модернизации «по заказу», а формируется и развивается веками под влиянием социальных, исторических, культурных и языковых факторов.

Добыча полезных ископаемых приводит к неизбежному вмешательству в жизнь коренных народов Арктики, устоявшуюся за сотни и тысячи лет. Сами промышленные предприятия занимают незначительные площади, однако вместе с транспортными коммуникациями и другими объектами инфраструктуры, постоянным вводом в строй новых месторождений взамен выбывающих в сферу их влияния попадают значительные территории. Ярким примером данного процесса является разработка углеводородов. Дисперсное, разбросанное на большой площади размещение месторождений нефти и газа, а также наличие здесь разветвленной сети трубопроводов приводят к широкому охвату территории при разработке ресурсов. Кроме отторжения земельных угодий, в таких районах происходит загрязнение водных ресурсов и атмосферы, то есть наносится ущерб всему комплексу условий, составляющих основу традиционной системы жизнедеятельности и жизнеобеспечения коренного населения.

С точки зрения многих наблюдателей, традиционный уклад и современный мир в Арктике вступают в непримиримое противостояние. Проживающие здесь коренные народы, составляющие большинство населения в северных территориях ряда государств, а также сохранившие частичный политический и экономический контроль над этими территориями, предпринимают значительные усилия для поиска компромисса в отношениях с национальными государствами и промышленными корпорациями.

Язык является одним из важнейших элементов культуры и средств формирования идентичности любого народа, однако, для малых народов это актуально в значительно большей степени. Языки малых народов не участвуют в формировании глобальной идентичности поликультурного мира со стирающимися границами, являются в определённом смысле «вещью в себе» и в отличие от международных языков отражают не тенденции населения Земли в целом с его нарастающей социальной мобильностью, а картину мира сообщества, внутри которого существуют в «законсервированном виде».

В современном языкознании принято считать, что каждый язык отражает свою особенную картину мира. Поэтому в лингвистике говорится о языковой картине мира. В словах языка каждого отдельного народа отражено, как был увиден и понят мир. Особенно хорошо это отражается в лексике языков малых народов. Для носителей эскимосских языков снег является одним из базовых понятий мира. Потому в их языках присутствуют отдельные слова, служащие названиями для падающего снега, снега из которого можно строить жилище, для мокрого снега. Для других народов настолько детальные обозначения снега не нужны. В некоторых языках коренных африканских племен своего слова «снег» нет вообще [5].

Освоение арктических территорий имеет не только экономические и технические, но также и социальные, а ещё лингвистические аспекты. Освоение северных зон автоматически подразумевает вступление в межэтнические контакты с коренными жителями арктических территорий и вступление с ними в профессиональное и социальное взаимодействие. Учитывая, что основным средством любой коммуникации является язык, именно лингвистический её аспект представляется одним из наиболее важных.

В данной статье мы рассмотрим группу эскимосских языков, наиболее общие их особенности и характеристики, а также перспективы их развития и их место в межэтнических контактах. Помимо этого ставится задача выделить наиболее существенные лингвистические особенности, характеризующие данную языковую группу. 


\section{Филология: научные исследования 1(17) • 2015}

Несмотря на то, что люди севера владеют и свободно разговаривают на государственных языках своих стран, их национальные языки представляют интерес в виду самобытности представленной ими культуры, неотъемлемой частью которой является язык.

На группе эскимосских языках в качестве родных говорят в четырёх государствах мира. К этим странам относятся Россия (Восточная Сибирь, Чукотский полуостров и Остров Ратманова), США (Аляска), Канада (северные провинции) и Дания (Гренландия).

Вместе с единственным в своей группе алеутским языком, который впрочем, имеет несколько диалектов, эскимосские языки представляют эскимосско-алеутскую языковую семью, которую также называют эксалеутской. Учёные из Аляски полагают, что алеутский язык откололся от эскимосских не ранее четырёх тысяч лет назад. Многие алеутские слова, тем не менее, имеют схожие корни с аналогичными из эскимосских языков.

Антропологами предполагается, что эскимосы, являющиеся коренным народом, населяющим арктические территории, являются монголоидами арктического типа. Самоназвание этого народа инуиты, а слово «эскимос» (эскиманциг) пришло из языков индейских племён и означает «сыроед», «тот, кто ест рыбу». Так стали сначала называться эскимосы Америки, а потом и все остальные.

Языки эскимосов России, Гренландии и Северной Америки обладают разной письменностью. Языки российских эскимосов были переведены на кириллицу в тридцатые годы прошлого столетия, как и все языки народов СССР. Эскимосы Гренландии используют латиницу, при этом в алфавите и тех и других есть дополнительные буквы с диакритическими знаками. У североамериканских эскимосов письменность на основе своих особых символов. Следует отметить, что при наличии письменности эти языки не обладают богатой литературной традицией.

Среди грамматических и лексических особенностей эскимосских языков, отличающих их от русского, английского и очень похожего на английский датского, являющегося государственным языком на острове Гренландия, можно выделить следующие.

1) Ярко выраженная полисинтетичность, то есть возможность корней присоединять большое количество морфем.

2) Полное превалирование суффиксов над приставками. Приставка как морфема существует только в языке инуктикут, на котором говорят в Гренландии.
3) В эскимосских словах может быть не более одного корня.

4) За счёт активной суффиксации количество корней в этих языках относительно мало.

5) В эскимосских языках есть понятие нейтрального корня. Это корни без лексического значения, нетипичные для других языков. Нейтральный корень используется, когда значение следующей за корнем морфемы выражается само ей самой. Наиболее распространенные значения таких морфем - «думать», «говорить», «иметь», «хотеть»и т.д.. Здесь следует отметить, что в других языках аффиксы имеют обобщенное значение и не могут выражать его самостоятельно.

6) Падеж существительных, а также лицо и залог глагола выражаются суффиксами, а не окончаниями.

7) В главных и придаточных частях предложения всегда употребляются разные формы глаголов. Как видно из этого перечня, эскимосские языки весьма специфичны с точки зрения грамматики. В них существуют явления, которых нет в европейских языках, что делает эскимосские языки трудными для освоения представителями других национальностей и культур $[6 ; 7 ; 8 ; 9 ; 10]$.

Лексика эскимосских языков тоже нетипична для европейцев. В виду удалённости и относительной труднодоступности говорящих на них, в них почти не проникли заимствованные слова, а также греческие и латинские корни, являющиеся международными и понятными для носителей разных языков. Лексическая система эскимосских языков формировалась на протяжении веков весьма обособлено. Отражение социокультурного опыта народа языком происходит в основном за счёт его лексики. Например, в языке гренландских эскимосов около пятидесяти слов, обозначающих снег в разных его проявлениях (сюда же включается и лёд).

Всё это, как уже отмечалось, затрудняет изучение эскимосских языков другими народами, а соответственно и распространение их в остальном мире. Фактическое неиспользование этих языков в межъязыковой коммуникации обусловливает отсутствие мотивации обычных людей к их изучению. Как неродными языками, освоенными посредством академического изучения ими владеет очень узкий круг специалистов, которые называются эскимологами. Эскимология, соответственно - область знания об эскимосской культуре. Причём эскимологию можно рассматривать как частную лингвистику (наравне со 


\section{Фольклор}

славистикой, англистикой, германистикой, романистикой, тюркологией и т.д.), если речь идёт именно о языке, так и интегрированную сферу гуманитарного знания, включающую в себя социологические, культурологические и исторические аспекты.

Эскимосские языки делятся на две подгруппы: юпикскую и инуитскую, при этом инуитская значительно более распространена. На инуитских языках говорят около 100.000 человек - северное население Канады и население Гренландии. Юпикские языки распространены на территории Аляски и России, но численность их носителей примерно в десять раз меньше. Но даже цифра в 100.000 носителей позволяет говорить о том, что эскимосские языки можно определить как малочисленные, то есть те, которые являются средством коммуникации малых народов, не обладающих собственным государством, и не используются в качестве средства межкультурной и межъязыковой коммуникации представителями других национальностей.

Причём именно на территории нашей страны эти языки находятся под угрозой исчезновения. В России носителей эскимосских языков (сибирская подгруппа юпикской группы) ничтожно мало, в то время как на территории Северной Америки и Гренландии носители этих языков (аляскинская подгруппа юпикской группы и инуитская группа) эскимосы представляют собой пусть и малые, но относительно социально-стабильные общности. Они живут в регионах с относительно благоприятными социально-экономическими условиями, что позволяет им не уезжать с Крайнего Севера и не переходить полностью на государственный язык своей страны, а сохранять и развивать свои традиции, передавая их из поколения в поколение.

Тем не менее в условиях глобализации многие эскимосы всё равно всё чаще пользуются государственными языками территорий, на которых проживают (русский, английский и датский). Язык считается мёртвым, если он больше не служит средством общения нации. Представляется, что фактически язык умирает, если не остаётся хотя бы двух его носителей, поскольку если им владеет всего один человек - язык уже не может выполнять свою основную функцию - коммуникативную.

Языки отличаются друг от друга не только особенностями фонетического и грамматического строя, словарным составом, степенью распространённости и числом носителей, но и характером и интенсивностью взаимодействия друг с другом. Язык - живое явление, он живёт вместе с его носителями и вступает в контакт с другими языками как только люди, говорящие на них вступают в межкультурную коммуникацию. Подобно тому, как люди, их культуры оказывают взаимодействие друг на друга, точно так же воздействуют друг на друга их языки.

Совершенно очевидно, что чем больше у сообщества, говорящего на языке социальных, торговых, деловых и профессиональных контактов с представителями других культур, тем больше влияния испытывает или оказывает их язык в зависимости от своего статуса. Наоборот, обособленные сообщества сохраняют свой язык неизменным на протяжении многих веков. Например, на севере исландский является одним из наименее изменившихся европейских языков с древних времён в виду географической удалённости людей говорящих на нём от континентальной Европы. Современный исландец может с лёгкостью понимать древнеисландские тексты, в то время, как, например, для англичанина тексты на древнеанглийском мало понятны. Одним из естественных процессов, происходящих вследствие межкультурной коммуникации, является заимствование языками слов других языков.

Из-за географической удалённости и относительной обособленности эскимосских народов, слова эскимосского происхождения не перешли в другие языки. Среди общеупотребительной лексики стандартного русского и английского языка нет эскимосских слов. Однако существуют эскимосские экзотизмы.

Экзотизмами называются слова, обозначающие особенные культурные, социальные и другие реалии народов, свойственные только этим нациям. Такие слова нельзя перевести на другой язык, поскольку в культуре других языков отсутствует подобное явление. Их можно перевести только описательно или вместо этого использовать заимствованное слово - экзотизм.

Все реалии любого народа, в том числе и эскимосского, можно условно разделить на две категории. К первой будут относиться те, что широко рядовым людям известны за пределами данной культуры. Ко второй относятся реалии, которые за пределами данного языкового сообщества известны только специалистам, а не широким массам.

Общеизвестных эскимосских реалий в русском языке немного. Среди них, например, «иглу» - традиционное эскимосское жилище из блоков льда и снега, а также «анорак» - теплая куртка без застёжки, надеваемая через голову с большим карманом на груди типа «кенгуру». 


\section{Филология: научные исследования 1(17) • 2015}

К малоизвестным эскимосским реалиям относятся, например, блюда национальной кухни: акутак (эским. «мороженое») - взбитый жир с ягодами, «аюк» - лечебный чай из багульника; национальные праздники: «атыгак» - праздник начала весенней охоты, «наскуныхкылык» - праздник окончания охоты на моржей и многие другие.

C повышением внимания мирового сообщества к проблемам коренных арктических народов, их лидеры выдвигают определённые требования, что может иметь значимые политические и экономические последствия. Зарубежный опыт нефтепромышленного освоения Аляски и долины канадской реки Маккензи (Канада) показывает, что политическая активность коренного арктического населения на фоне перспектив экономического роста и возникающие земельные споры и длительные поиски компромиссов могут надолго затормозить реализацию крупных проектов.

С точки зрения оптимизации отношений между государством, промышленными корпорациями и коренными народами необходима выработка корректной и реалистичной политики, адекватно выражающей интересы всех заинтересованных субъектов. В этой связи проблемы межкультурной и межэтнической коммуникации также представляются актуальными. Конкретные усилия государства по поддержанию и распространению эскимосских языков могут стать одним из факторов нахождения компромисса между промышленным освоением Севера и сохранением культур его коренных народов.

Представляется, что важными принципами в политики по отношению к народам Севера являются следующие принципы.

1) Субъектами программирования, а также многочисленных концепций развития этих народов должны выступать они сами, а не внешние по отношению к ним субъекты;

2) Народы Севера не должны воспринимаются как однородный укрупненный объект управленческого воздействия;

3) Акцент должен делаться не только на внешних источниках их развития, на создании материальных объектов, но и на сохранение и приумножение их культурных ценностей, в том числе языка.

В современных условиях необходима реализация нового концептуального подхода. Его суть должна состоять в субъектно-ориентированной политике в отношении народов Севера. Главное в данном случае - создать систему учета социокуль- турного потенциала каждого из них и механизм его задействования в процессе современного развития.

Субъектно-ориентированный подход не заменяет, а дополняет объектно-ориентированный. Ясно, что нельзя отказываться от строительства школ, детских садов, других объектов социальной инфраструктуры, создания условий для развития экономических структур и т.д. Но всё более очевидным становится то, что этим нельзя ограничиваться [11].

Осваивая российскую Арктику, нам необходимо осваивать эскимосские языки и создавать возможности не только для их распространения на Севере, но и в стране в целом. Последнее подразумевает создание факультетов и кафедр в инязах и других крупных с привлечением немногочисленных отечественных специалистов-лингвистов по данному направлению, а также зарубежных эскимологов для подготовки профессионалов в различных областях, которые владели бы хорошо эскимосскими языками как иностранными. В настоящее время эскимосские языки систематически преподаются в ряде северных школ, в анадырском педагогическом училище и в немногочисленных институтах народов Севера (Петербург, Красноярск).

В Аляске, например, с 1972 г., когда начал действовать закон о двуязычном образовании, работает огромное количество курсов, семинаров, тренингов и академических программ, направленных на подготовку людей, владеющих эскимосскими языками и готовых преподавать их в школах, где их изучение обязательно.

Обособленность и необычайный колорит, вызванный условиями, в которых живут эскимосские народы, делает эту самобытную культуру привлекательной для познавательного туризма [12]. Однако интерес именно к эскимосским языкам за пределами соседних с эскимосскими территорий в мире очень мал, а в нашей стране его вообще почти нет. Они изучаются как иностранными только специалистами эскимологами. В Интернете доля сайтов на эскимосском языке ничтожно мала, а в Рунете найти качественные материалы о них на русском языке не представляется возможным, в отличие от английского (американские и канадские сайты). Освоение арктических территорий могло бы способствовать культурному обмену, и придать мотивацию людям, бывающим на севере в виду своей профессиональной деятельности, мотивацию к изучению этих языков для более эффективного социального взаимодействия с представителями эскимосских народов в процессе межэтнических контактов. 


\section{Список литературы:}

1. Гусев Д.А. Либерализм, православие и национальная идея в условиях переходного периода и кризиса современного российского общества // Философская мысль. 2015. № 2. С. 25-62.

2. Гатиатуллина Э.Р., Тайсаев Д.М. Механизм демаргинализации в современных социально-экономических условиях // Вестник Университета Российской академии образования. 2015. № 1. С. 68-75.

3. Рибокене Е.В. Институциональная среда постиндустриального информационного общества // Вестник Московского университета им. С.Ю. Витте. Серия 1: Экономика и управление. 2014. № 2(8). С. 137-139.

4. Рибокене Е.В. Экономическое поведение потребителей в условиях транзитивной экономики России: Дис. ... канд. экон. наук. Саратов, 2001.

5. Гатиатуллина Э.Р. Идентичность как категория социальной философии: Дис. ... канд. филос. наук. Нальчик, 2012.

6. Богораз В.Г. Материалы по языку азиатских эскимосов. Л., 1949.

7. Вахтин Н.Б. Гренландский язык // Языки мира. Палеоазиатские языки. М., 1997.

8. Вахтин Н.Б. Инуитов Аляски языки // Языки мира. Палеоазиатские языки. М., 1997.

9. Меновщиков Г.А. Эскимосов Берингова пролива язык // Языки мира. Палеоазиатские языки. М., 1997.

10. Меновщиков Г. А. Язык сиреникских эскимосов (фонетика, морфология, тексты и словарь). М.; Л., 1964.

11. Попков Ю.В. Коренные народы Севера в условиях глобализации // Век глобализации. 2014. № 1. С. 111-123.

12. Рыбакова Н.А. Воспитание у школьников качеств самоактуализирующейся личности на уроках музыки // Педагогика искусства. 2012. № 2. С. 119-125.

13. Лазуткина Л.Н. Роль коммуникативной культуры в реализации профессионального общения // Экономика. Предпринимательство. Окружающая среда. 2006. Т. 4. С. 47-50.

14. Гатиатуллина Э.Р., Орлов А.Н. Маргинализация как социальный феномен в контексте современных глобализационных процессов // Вестник Московского университета им. С.Ю. Витте. Серия 1: Экономика и управление. 2013. № 4(6). С. 63-68.

15. Малышева А.Н. Аддитивные полезности в теории выбора альтернатив // Известия Южного федерального университета. Технические науки. 2010. № 12(113). С. 83-88.

16. Пробин П.С. Отечественная образовательная реформа в контексте современной конъюнктуры рынка труда: контуры интерпретаций // Социодинамика. 2015. № 3. С. 1-26.

17. Рыбакова Н.А. Теоретические основы и технология художественно-творческой самоактуализации учителя музыки: Автореф. дис. ... докт. пед. наук. Барнаул, 2006.

18. Семенов А.В., Руденко Ю.С., Разовский Ю.В. Рентное мировоззрение арктического развития России // Вестник Московского университета им. С.Ю. Витте. Серия 1: Экономика и управление. 2014. № 5(11). С. 11-20.

19. Семенов А.В., Руденко Ю.С., Разовский Ю.В. Стратегические приоритеты арктической геополитики России // Вестник Московского университета им. С.Ю. Витте. Серия 1: Экономика и управление. 2014. № 5(11). С. 3-10.

20. Севоян Д.Г. К вопросу об основных сферах деятельности национально-культурных автономий // Политика и общество. 2014. № 12. С. 1479-1484. (DOI: 10.7256/1812-8696.2014.12.14087).

21. Долгов К.М. Культура в эпоху глобализации // Философия и культура. 2011. № 9. С. 38-43.

22. Гуревич П.С. Глобализация и мультикультурализм // Философия и культура. 2012. № 8. С. 4-5.

23. Бунчук В.Л. Федерализм и региональное развитие России в «Стратегии 2020» // Политика и общество. 2013 . № 10. C. 1221-1223. (DOI: 10.7256/1812-8696.2013.10.7268).

24. Зайцев А.В. Институционализация диалога государства и гражданского общества в контексте нормативной модели диалогической демократии // Социодинамика. 2014. № 7. C. 64-82. (DOI: 10.7256/2409-7144.2014.7.12541. URL: http://www.e-notabene.ru/pr/article_12541.html).

\section{References (transliteration):}

1. Gusev D.A. Liberalizm, pravoslavie i natsional'naya ideya v usloviyakh perekhodnogo perioda i krizisa sovremennogo rossiiskogo obshchestva // Filosofskaya mysl'. 2015. № 2. S. 25-62.

2. Gatiatullina E.R., Taisaev D.M. Mekhanizm demarginalizatsii v sovremennykh sotsial'no-ekonomicheskikh usloviyakh // Vestnik Universiteta Rossiiskoi akademii obrazovaniya. 2015. № 1. S. 68-75.

3. Ribokene E.V. Institutsional'naya sreda postindustrial'nogo informatsionnogo obshchestva // Vestnik Moskovskogo universiteta im. S.Yu. Vitte. Seriya 1: Ekonomika i upravlenie. 2014. № 2(8). S. 137-139.

4. Ribokene E.V. Ekonomicheskoe povedenie potrebitelei v usloviyakh tranzitivnoi ekonomiki Rossii: Dis. ... kand. ekonom. nauk. Saratov, 2001.

5. Gatiatullina E.R. Identichnost' kak kategoriya sotsial'noi filosofii: Dis. ... kand. filos. nauk. Nal'chik, 2012.

6. Bogoraz V.G. Materialy po yazyku aziatskikh eskimosov. L., 1949.

7. Vakhtin N.B. Grenlandskii yazyk // Yazyki mira. Paleoaziatskie yazyki. M., 1997.

8. Vakhtin N.B. Inuitov Alyaski yazyki // Yazyki mira. Paleoaziatskie yazyki. M., 1997.

9. Menovshchikov G.A. Eskimosov Beringova proliva yazyk // Yazyki mira. Paleoaziatskie yazyki. M., 1997.

10. Menovshchikov G.A. Yazyk sirenikskikh eskimosov (fonetika, morfologiya, teksty i slovar'). M.; L., 1964.

11. Popkov Yu.V. Korennye narody Severa v usloviyakh globalizatsii // Vek globalizatsii. 2014. № 1. S. 111-123. 


\section{Филология: научные исследования 1(17) • 2015}

12. Rybakova N.A. Vospitanie u shkol'nikov kachestv samoaktualiziruyushcheisya lichnosti na urokakh muzyki // Pedagogika iskusstva. 2012. № 2. S. 119-125.

13. Lazutkina L.N. Rol'kommunikativnoi kul'turyv realizatsii professional'nogoobshcheniya //Ekonomika. Predprinimatel'stvo. Okruzhayushchaya sreda. 2006. T. 4. S. 47-50.

14. Gatiatullina E.R., Orlov A.N. Marginalizatsiya kak sotsial'nyi fenomen v kontekste sovremennykh globalizatsionnykh protsessov // Vestnik Moskovskogo universiteta im. S.Yu. Vitte. Seriya 1: Ekonomika i upravlenie. 2013. № 4(6). S. 63-68.

15. Malysheva A.N. Additivnye poleznosti v teorii vybora al'ternativ // Izvestiya Yuzhnogo federal'nogo universiteta. Tekhnicheskie nauki. 2010. № 12(113). S. 83-88.

16. Probin P.S. Otechestvennaya obrazovatel'naya reforma v kontekste sovremennoi kon"yunktury rynka truda: kontury interpretatsii // Sotsiodinamika. 2015. № 3. S. 1-26.

17. Rybakova N.A. Teoreticheskie osnovy i tekhnologiya khudozhestvenno-tvorcheskoi samoaktualizatsii uchitelya muzyki: Avtoref. dis. ... dokt. pedag. nauk. Barnaul, 2006.

18. Semenov A.V., Rudenko Yu.S., Razovskii Yu.V. Rentnoe mirovozzrenie arkticheskogo razvitiya Rossii // Vestnik Moskovskogo universiteta im. S.Yu. Vitte. Seriya 1: Ekonomika i upravlenie. 2014. № 5(11). S. 11-20.

19. Semenov A.V., Rudenko Yu.S., Razovskii Yu.V. Strategicheskie prioritety arkticheskoi geopolitiki Rossii // Vestnik Moskovskogo universiteta im. S.Yu. Vitte. Seriya 1: Ekonomika i upravlenie. 2014. № 5(11). S. 3-10.

20. Sevoyan D.G. K voprosu ob osnovnykh sferakh deyatel'nosti natsional'no-kul'turnykh avtonomii // Politika i obshchestvo. 2014. № 12. S. 1479-1484. (DOI: 10.7256/1812-8696.2014.12.14087).

21. Dolgov K.M. Kul'tura v epokhu globalizatsii // Filosofiya i kul'tura. 2011. № 9. S. 38-43.

22. Gurevich P.S. Globalizatsiya i mul'tikul'turalizm // Filosofiya i kul'tura. 2012. № 8. S. 4-5.

23. Bunchuk V.L. Federalizm i regional'noe razvitie Rossii v «Strategii 2020»// Politika i obshchestvo. 2013. № 10. S. 12211223. (DOI: 10.7256/1812-8696.2013.10.7268).

24. Zaitsev A.V. Institutsionalizatsiya dialoga gosudarstva i grazhdanskogo obshchestva v kontekste normativnoi modeli dialogicheskoi demokratii // Sotsiodinamika. 2014. № 7. S. 64-82. (DOI: 10.7256/2409-7144.2014.7.12541. URL: http:// www.e-notabene.ru/pr/article_12541.html). 